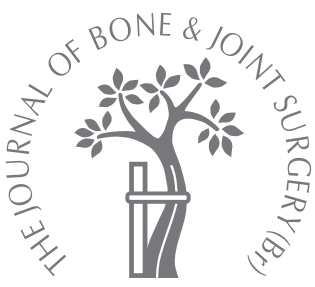

- CASE REPORT

\title{
Survival of ceramic bearings in total hip replacement after high-energy trauma and periprosthetic acetabular fracture
}

S. Salih,

V. A. Currall,

A. J. Ward,

T. J. S. Chesser

From Frenchay

Hospital, Bristol,

England
S. Salih, MA, Orthopaedic

Core Trainee

V. A. Currall, MRCS(Eng),

Orthopaedic Registrar

A. J. Ward, FRCS, Consultant

Orthopaedic Surgeon

T. J. S. Chesser,

FRCS(Trauma \& Orth),

Consultant Orthopaedic

Surgeon

Pelvic and Acetabular

Reconstruction Unit,

Department of Trauma and

Orthopaedics

North Bristol NHS Trust,

Frenchay Hospital, Bristol BS16

1LE, UK.

Correspondence should be sent to Mr T. J. S. Chesser; e-mail:

Tim.Chesser@nbt.nhs.uk

(C)2009 British Editorial Society of Bone and Joint Surgery doi:10.1302/0301-620X.91B11. $22737 \$ 2.00$

$J$ Bone Joint Surg $[\mathrm{Br}]$

2009;91-B:1533-5.

Received 21 April 2009;

Accepted 12 June 2009

\begin{abstract}
Surgeons remain concerned that ceramic hip prostheses may fail catastrophically if either the head or the liner is fractured. We report two patients, each with a ceramic-on-ceramic total hip replacement who sustained high-energy trauma sufficient to cause a displaced periprosthetic acetabular fracture in whom the ceramic bearings survived intact. Simultaneous fixation of the acetabular fracture, revision of the cementless acetabular prosthesis and exchange of the ceramic bearings were performed successfully in both patients. Improved methods of manufacture of new types of alumina ceramic with a smaller grain size, and lower porosity, have produced much stronger bearings.

Whether patients should be advised to restrict high-impact activities in order to protect these modern ceramic bearings from fracture remains controversial.
\end{abstract}

The use of ceramic-on-ceramic bearing total hip replacement (THR) has been advocated for younger patients with osteoarthritis because they wear less and last longer. ${ }^{1}$ However, previous reports of catastrophic failure of the ceramic bearing surfaces have limited the use of these implants. ${ }^{2,3}$ Consequently, many surgeons advise patients with hip implants to avoid activities which involve heavy impact. With earlier devices failure of the ceramic bearing was attributed to deficiencies in manufacture. These have subsequently been addressed. ${ }^{4}$

We report two patients with modern ceramic-on-ceramic THRs who sustained a periprosthetic acetabular fracture after highenergy trauma and in whom the retrieved ceramic bearings were not damaged by the impact. Each was treated successfully by simultaneous fixation of the acetabular fracture, revision of the acetabular prosthesis and exchange of the ceramic bearings.

\section{Case reports}

Case 1. A 45-year-old man underwent a left hybrid THR (Trident cementless acetabular shell, alumina ceramic-on-ceramic bearings Exeter cemented femoral component; Stryker, Newbury, United Kingdom) for osteoarthritis without complication.

Three years later he crash-landed his glider and, in a seated position, sustained two sequential impacts at an estimated speed of 60 miles per hour. He had a combined pelvic ring and acetabular injury, consisting of bilateral sacral fractures, diastasis of the symphysis pubis and a displaced transverse fracture of the left acetabulum (Fig. 1a). This periprosthetic fracture of the acetabulum was associated with displacement of the acetabular component of the THR. After initial stabilisation with a pelvic external fixator, he was transferred to the regional pelvic and acetabular trauma unit for reconstructive surgery. The pelvic ring was initially stabilised by closed reduction and percutaneous fixation of both sacroiliac joints with $6.5 \mathrm{~mm}$ cannulated screws and then by open reduction of the symphysis pubis and fixation with a six-hole plate and screws. Using a Kocher-Langenbeck approach, the acetabular component was removed and the acetabular fracture reduced and stabilised with a lag screw in the anterior column and a lag screw and plate applied to the posterior column. Morcellised allograft bone was impacted into the reconstructed acetabulum and a new Trident cementless multihole hemispherical acetabular shell (Stryker UK) was inserted and secured with screws. A new ceramic liner was inserted and the $32 \mathrm{~mm}$ ceramic modular head was exchanged.

Post-operatively, he was mobilised touch weight-bearing on the left leg for six weeks and then partial weight-bearing for a further six weeks. He made an uneventful recovery. The pelvic and acetabular fractures healed and he regained full function of his hip (Fig. 1b).

Case 2. A 66-year-old man underwent an uncomplicated right hybrid THR (Trident and Exeter implants with alumina ceramic-onceramic bearings; Stryker UK) for osteoarthri- 


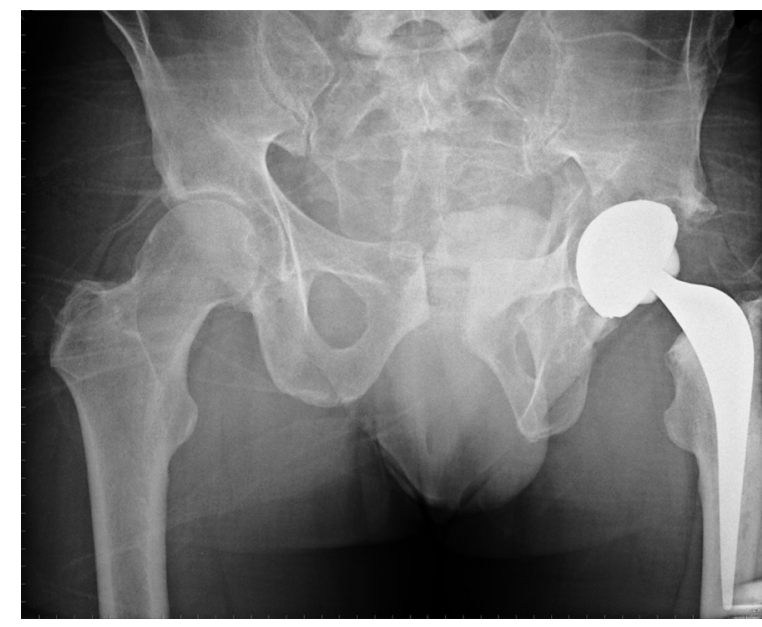

Fig. 1a

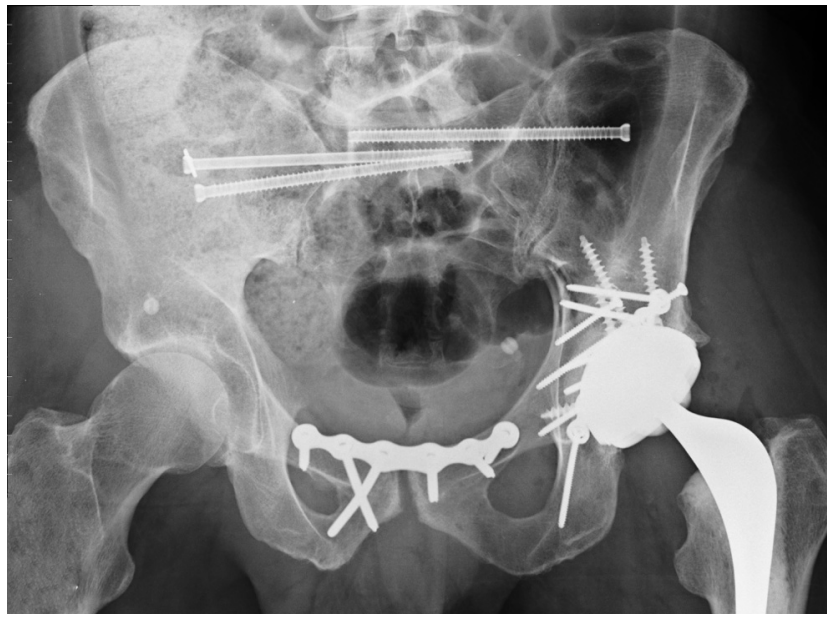

Fig. $1 b$

Case 1 - Anteroposterior pelvic radiographs showing a) diastasis of the pubic symphysis and a periprosthetic transverse fracture of the left acetabulum and b) fixation of the sacroiliac joint and pubic symphysis with reconstruction of the left acetabulum at follow-up at three months.

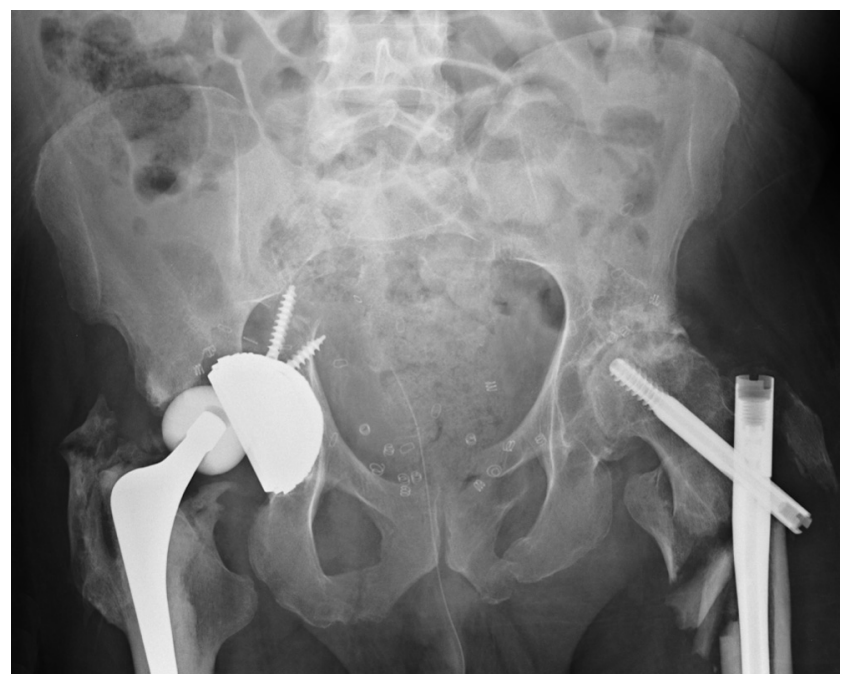

Fig. 2a

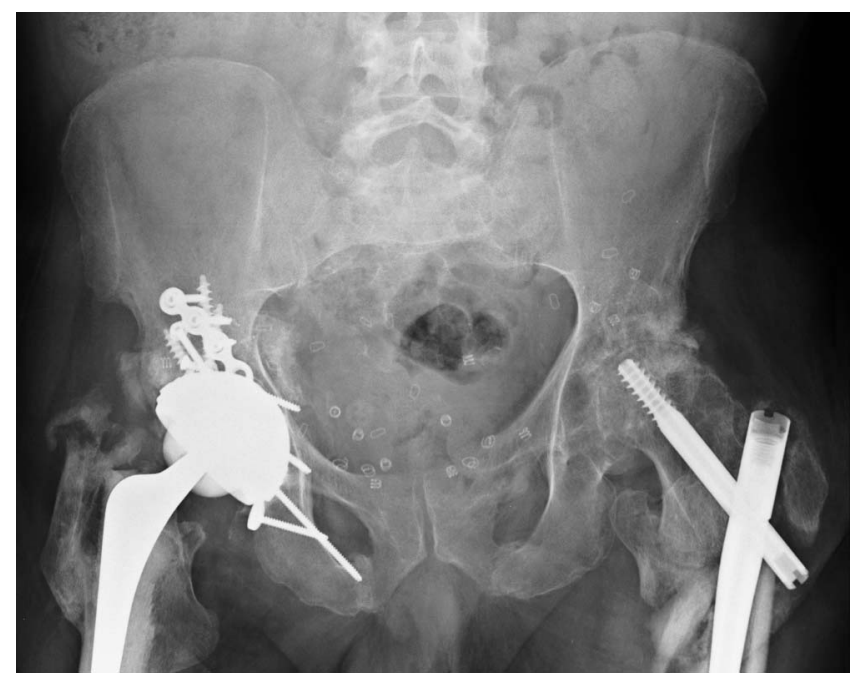

Fig. 2b

Case 2 - Anteroposterior pelvic radiographs showing a) the right transverse periprosthetic acetabular fracture and internal fixation of the left proximal femur and b) right acetabular reconstruction and revision.

tis. Two years later he was involved in a road-traffic accident and sustained an open fracture of the proximal left femur, closed fractures of the left scapula and right humerus and a displaced transverse periprosthetic fracture of the right acetabulum (Fig. 2a). Revision THR was performed through a Kocher-Langenbeck approach with removal of the cementless acetabular shell, ceramic liner and modular femoral head. Reduction and stabilisation of the acetabular fracture were undertaken with an anterior column screw and posterior column plate. A new cementless multihole Trident acetabular shell, ceramic liner and modular $32 \mathrm{~mm}$ head (Stryker UK) were used.
His recovery was delayed by his other injuries but, after six months, the acetabular fracture had united and he had recovered the function of his hip (Fig. 2b).

\section{Analysis of retrieved ceramic implants}

The retrieved acetabular and femoral head components were examined by their manufacturer (CeramTec AG, Plockingen, Germany). No macroscopic damage of the ceramic bearings was detected in either case. Dye-fluid treatment did not reveal surface cracks in either case or any other damage to the surface of the bearing in case 2. However, in case 1 , there were corresponding half-moon-shaped 


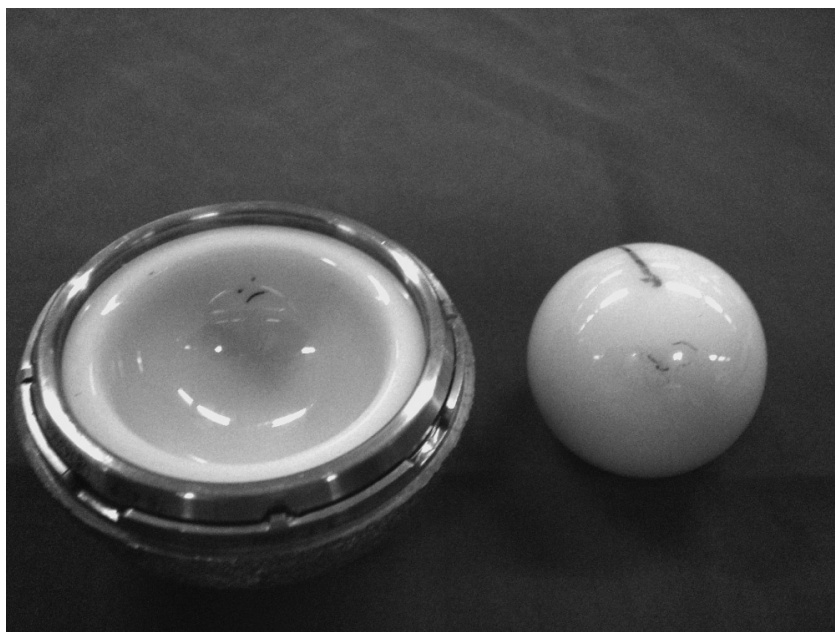

Fig. 3

Case 1 - Photograph of the ceramic liner and head stained with ink showing the slight surface defect thought to have been caused by the impact.

areas of 'surface deterioration' measuring $1 \mathrm{~mm}$ in length on both bearing surfaces. These were thought to have resulted from high-stress contact and shear of the two ceramic surfaces at the moment of impact (Fig. 3). The quality assurance investigation concluded that "no significant damage has been created on the parts which would have limited in vivo function".

\section{Discussion}

Ceramic hip components were introduced in the 1970 s. $^{5}$ Alumina ceramics are very hard, ionic and hydrophilic, 5,6 and have a very low rate of wear. ${ }^{7}$ The alumina wear particles are relatively biocompatible and smaller than those produced by metal-on-polyethylene prostheses, which may be associated with osteolysis and aseptic loosening., 2,3 Despite these favourable characteristics, some ceramic prostheses have failed catastrophically. ${ }^{2,3,8,9}$ The early ceramic bearings were manufactured with a larger grain size, high porosity and minor defects in the alumina surface, which reduced the strength of the ceramic. They had reported rates of fracture between $0 \%$ and $1.7 \% .3,10$ The importance of the manufacturing process and type of ceramic was highlighted by reports of a faulty batch of zirconia femoral head implants of which one-third fractured. ${ }^{4}$

New formulations of alumina ceramic are much stronger, with a smaller grain size and lower porosity. A recent review of 35000 cases has suggested that, with modern manufacturing techniques, the rate of fracture of ceramicon-ceramic bearings may be as low as $0.06 \%{ }^{11}$ These fractures have mostly been attributed to impingement of the neck of the femoral component on the rim of the ceramic liner.
In our two cases, despite the fact that a very high impact force acted on the ceramic bearings of the THR, no significant damage occurred to the bearing couple, while the surrounding bone failed resulting in a displaced periprosthetic fracture of the acetabulum. Human bone is weaker and less stiff than alumina oxide ceramics (strength $100 \mathrm{MPa}$ and $600 \mathrm{MPa}$, respectively). The periprosthetic fractures were successfully treated by simultaneous fixation of the acetabular fracture, revision of the acetabular prostheses and exchange of the ceramic bearings.

Most orthopaedic surgeons advise their patients with ceramic implants to avoid high-impact activities to minimise the risk of catastrophic failure. ${ }^{2,12}$ This advice may seem unrealistic in younger patients with higher functional demands. All ceramic prostheses have been non-destructively proof-tested since the early 1990s. ${ }^{13}$ The Food and Drug Administration in the United States sets a minimum burst strength of $48 \mathrm{kN}$ for alumina prostheses and recent implants have a tested burst strength of $98 \mathrm{kN} .^{6}$ These forces are greater than those observed under physiological conditions. ${ }^{14}$ Nonetheless, caution is still advisable since repeated high-impact stresses, rather than the single episode reported in our cases, may increase the risk of crack propagation and subsequent ceramic failure.

Although none of the authors has received or will receive benefits for personal or professional use from a commercial party related directly or indirectly to the subject of this article, benefits have been or will be received but will be directed solely to a research fund, foundation, educational institution, or other nonprofit organisation with which one or more of the authors are associated.

\section{References}

1. Ha TC, Koo KH, Jeong ST, et al. Cementless alumina-on-alumina total hip arthroplasty in patients younger than 50 years: a 5 -year minimum follow-up study. J Arthroplasty 2004;22:184-8.

2. Barrack RL, Burak C, Skinner HB. Concerns about ceramics in THA. Clin Orthop 2004:429:73-9.

3. Hannouche D, Nich C, Bizot $\mathbf{P}$, et al. Fractures of ceramic bearings: history and present status. Clin Orthop 2003;417:19-26.

4. Clarke IC, Manaka M, Green DD, et al. Current status of zirconia used in total hip implants. J Bone Joint Surg [Am] 2003;85-A(Suppl 4):73-84.

5. Hannouche D, Hamadouche $\mathbf{M}$, Nizard R, et al. Ceramics in total hip replacement. Clin Orthop 2005;430:62-71.

6. Sedel L. Evolution of alumina-on-alumina implants: a review. Clin Orthop 2000;379:48-54.

7. Skinner HB. Ceramic bearing surfaces. Clin Orthop 1999;369:83-91.

8. Habermann B, Ewald W, Rauschmann M, Zichner L, Kurth AA. Fracture of ceramic heads in total hip replacement. Arch Orthop Trauma Surg 2006;126:464-70.

9. Park YS, Hwang SK, Choy WS, et al. Ceramic failure after total hip arthroplasty with an alumina-on-alumina bearing. J Bone Joint Surg [Am]2006;88-A:780-7.

10. Koo KH, Ha YC, JUng WH, et al. Isolated fracture of the ceramic head after thirdgeneration alumina-on-alumina total hip arthroplasty. J Bone Joint Surg [Am] 2008;90A:329-36.

11. Tateiwa T, Clarke IC, Williams PA, et al. Ceramic total hip arthroplasty in the United States: safety and risk issues revisited. Am J Orthop 2008;37:26-31.

12. Simon JA, Dayan AJ, Ergas E, Stuchin SA, Di Cesare PE. Catastrophic failure of the acetabular component in a ceramic-polyethylene bearing total hip arthroplasty. $J$ Arthroplasty 1998;13:108-13.

13. Pfaff HG. Ceramic component failure and the role of proof testing. Clin Orthop 2000;379:29-33.

14. Maher SA, Lipman JD, Curley LJ, Gilchrist M, Wright TM. Mechanical performance of ceramic acetabular liners under impact conditions. J Arthroplasty 2003;18:936-41. 